\title{
Research of the variable natural potential of the wind and energy energy in the northern strip of the ukrainian carpathians
}

\author{
Anatoliy Tryhuba ${ }^{1}$, Oleg Bashynsky ${ }^{2}$, Ihor Garasymchuk ${ }^{3}$, Oleg Gorbovy ${ }^{3}$, Dariia \\ Vilchinska ${ }^{3}$ and Viktor Dubik ${ }^{3}$ \\ ${ }^{1}$ Lviv National Agrarian University, 80381 Dublyany, Ukraine \\ ${ }^{2}$ Lviv State University of Life Safety, 79007 Lviv, Ukraine \\ ${ }^{3}$ State Agrarian and Engineering University in Podilia, 32300 Kamianets-Podilskyi, Ukraine
}

\begin{abstract}
The expediency of studying the varying potential of wind and solar energy in the northern strip of the Ukrainian Carpathians is substantiated. The technique of conducting experiments to determine the natural potential of wind and solar energy is proposed and a model for determining the relative volumes of electricity generation by wind farms and solar electrical installations is developed. Based on the conducted research, according to the Drohobych meteorological station, an energy assessment of wind and solar energy resources in the northern strip of the Ukrainian Carpathians was performed. It is substantiated that the theoretical curves of distribution of wind velocity in separate quarters of the year in the territory of the northern strip of the Ukrainian Carpathians are described by the Weibull distributions. Based on the calculations, it is established that the highest total daily solar radiation is in the summer months. Daily graphs of the relative generation of electricity by wind farms and solar electric installations have been constructed. The expediency of formation of combined systems of energy supply of objects from wind and solar energy in the northern strip of the Ukrainian Carpathians has been established. The substantiated patterns of change in the natural potential of wind and solar energy, as well as the graphs of the relative generation of electricity from them, will significantly speed up managerial decisions and improve their quality.
\end{abstract}

\section{Introduction}

The relevance of the problem of efficient energy supply of objects from renewable sources of wind and solar energy is confirmed by the fact that individual territories have considerable uneven supply of this energy in different seasons of the calendar year, as well as with respect to their individual species [1-11]. In addition, the creation of energy systems for renewable energy sources and wind to meet consumer needs is a pressing issue, given the recent trends in fossil fuel prices. The peculiarity of creating small energy systems using renewable wind and solar energy is that individual installations do not operate on a single grid, but individually, ie provide electricity to a limited number of consumers. That is why an adequate assessment of their potential is possible if appropriate research is carried out 
taking into account specific natural production conditions [12-21].

Conducted scientific studies by Ukrainian and foreign scientists have made it possible to solve many problems of efficient use of non-traditional and renewable energy sources [59]. Among these are studies related to the creation of efficient energy systems based on the use of renewable wind and solar energy, operating in deterministic or stochastic conditions [10-11]. At the same time, it has been proved that there is a need to substantiate mathematical models of the changing potential of wind and solar energy in different regions of the world [1-4]. They are at the heart of the modeling and optimization of energy systems for wind and solar energy.

According to this, the substantiation of mathematical models of natural potential and the possibility of wind and sun energy production in the northern lane of the Ukrainian Carpathians has important scientific and practical value.

The purpose of this work is to substantiate mathematical models of natural potential and to simulate the production of wind and solar energy in the northern lane of the Ukrainian Carpathians.

\section{Theoretical backgrounds}

The energy characteristics of solar and wind resources have a significant impact on the functional performance of renewable energy systems. The analysis of literature sources suggests that to account for the characteristics of solar radiation and wind resources in different energy supply projects, two methods are used: 1) generate retrospective meteorological data for previous years; 2) create models of meteorological conditions. We used the first method of energy estimation of solar radiation and wind energy resources.

To study the random flow, one must be able to estimate the random deviations (fluctuations) of the intensity of the solar radiation and wind. Statistical processing is carried out equally for stationary and non-stationary processes, with the only difference being that the non-stationary flow is investigated not by absolute value but by relative or absolute deviation.

During mathematical processing of a given parameter by experimental (empirical) data, which is limited in number, it is impossible to determine the true values of the distribution characteristics, and therefore determine the so-called estimates of mathematical expectation, variance, root mean square deviation and coefficient of variation. These estimates are called statistical characteristics.

The empirical distributions are consistent with the theoretical criteria specially developed in theory [13]. Arrange the data of the empirical series in ascending order and thus form a variational series:

$$
Y_{1}<Y_{2}<\ldots<Y_{N}
$$

The variational series is divided into $k$ intervals. The number of intervals is determined by the formula:

$$
k=1+3,32 \lg N,
$$

where $N$ - number of experiments (sample).

The interval interval is calculated by the formula:

$$
\Delta Y=\frac{Y_{N}-Y_{I}}{k} .
$$


The results of the calculations are recorded in Table 1.

Table 1. Results of calculation of statistical characteristics of natural potential of wind and solar energy

\begin{tabular}{|c|c|c|c|c|c|c|}
\hline \multirow{2}{*}{$\begin{array}{c}\text { № } \\
\text { p/e }\end{array}$} & Indicator & \multicolumn{5}{|c|}{ № of interval } \\
\cline { 2 - 6 } & 1 & 2 & $\ldots$ & $k-1$ & $k$ \\
\hline 1 & $\begin{array}{c}\text { The interval } \\
Y_{i}^{H} \ldots Y_{i}^{B}\end{array}$ & $Y_{1}^{H} \ldots Y_{1}^{B}$ & $Y_{2}^{H} \ldots Y_{2}^{B}$ & $\ldots$ & $Y_{k-1}^{H} \ldots Y_{k-1}^{B}$ & $Y_{k}^{H} \ldots Y_{k}^{B}$ \\
\hline 2 & $\begin{array}{c}\text { The middle of the } \\
\text { interval, } Y_{i}\end{array}$ & $Y_{1}$ & $Y_{2}$ & $\ldots$ & $Y_{k-1}$ & $Y_{k}$ \\
\hline 3 & frequency, $m_{i}$ & $m_{1}$ & $m_{2}$ & $\ldots$ & $m_{k-1}$ & $m_{k}$ \\
\hline 4 & $\begin{array}{c}\text { empirical frequency } \\
P_{i}=\frac{m_{i}}{N}\end{array}$ & $P_{1}$ & $P_{2}$ & $\ldots$ & $P_{k-1}$ & $P_{k}$ \\
\hline 5 & $Y_{i} \times P_{i}$ & $Y_{1} \times P_{1}$ & $Y_{2} \times P_{2}$ & $\ldots$ & $Y_{k-1} \times P_{k-1}$ & $Y_{k} \times P_{k}$ \\
\hline 6 & $\left(Y_{i}-Y_{c}\right)^{2} \times P_{i}$ & $\left(Y_{1}-Y_{c}\right)^{2} * P_{1}$ & $\left(Y_{2}-Y_{c}\right)^{2} \times P_{2}$ & $\ldots$ & $\left(Y_{k-1}-Y_{c}\right)^{2} \times P_{k-1}$ & $\left(Y_{k}-Y_{c}\right)^{2} \times P_{k}$ \\
\hline
\end{tabular}

The frequency is then determined $m_{i}$ by a random variable at each interval, and an empirical frequency is calculated $P_{i}$ :

$$
P_{i}=\frac{m_{i}}{N}
$$

The following are the statistical characteristics (estimates):

mathematical expectation

$$
Y_{c}=\sum_{i=1}^{k} Y_{i} \cdot P_{i}
$$

Dispersion:

$$
D=\sum_{i=1}^{k}\left(Y_{i}-Y_{c}\right)^{2} \cdot P_{i}
$$

standard deviation:

$$
\delta=\sqrt{\sum_{i=1}^{k}\left(Y_{i}-Y_{c}\right)^{2} \cdot P_{i}}
$$

coefficient of variation:

$$
\begin{aligned}
& v=\frac{\delta}{Y_{c}} ; \\
& v=\frac{\delta}{Y_{c}-Y_{\text {зи }}} .
\end{aligned}
$$

where $Y_{3,}$ - displacement of the scatter zone of random magnitude $Y$ relative to zero.

The estimate of the coefficient of variation according to the formula is calculated if the scatter zone of the exponent $Y$ has a displacement relative to zero. Provided that $Y_{1}$ of variation series is correct (is included in the sample), it is considered that: $Y_{3 u}=Y_{1}$.

Checking the extreme values of the variation series for their sampling. The first $Y_{1}$ and 
the last $Y_{N}$ values of the variance series are needed to be checked for their sample (whether they are correct) according to Irwin's criterion [13]:

$$
\begin{array}{r}
\lambda_{d l}=\frac{1}{\delta}\left(Y_{2}-Y_{I}\right), \\
\lambda_{d N}=\frac{1}{\delta}\left(Y_{N}-Y_{N-I}\right) .
\end{array}
$$

Compare the calculated values with the table values [16] for a given probability $(0,95<\alpha<0,99)$ and the number of experiments $N$. If $\lambda_{d} € \lambda_{T}$, is received, then it is considered that the extreme value is not mistaken. Otherwise, it is removed from the variation series and the calculation of statistical characteristics is repeated.

Check the sample size for normal distribution. With considerable cost and time to perform individual experiments (to determine each value $Y$ ) it is important to carry out a quantity sufficient to estimate the statistical characteristics. Mostly the number $N_{d}$ of experiments for the normal distribution is determined on the basis of ensuring that the relative error $(\delta)$ in the estimation of the mathematical expectation with a given confidence probability $(\alpha=0,8 \ldots 0,95)$ does not exceed $10-20 \%$ :

$$
N_{d}=\frac{v^{2} t^{2}}{\delta^{2}}
$$

where $t$ - quantile of normal distribution.

Compare the calculated value $N_{d}$ with an actual one and make a conclusion about expediency of carrying out additional experiments.

Construction of a histogram (polygon) of the distribution of the studied indicator and hypothesis about the theoretical pattern of distribution. According to the variation series, plot the relationship between the investigated value and the empirical frequency. For this purpose, the upper, lower and average values of the intervals $\mathrm{Y}$ are determined by a certain measure on the abscissa axis. The y-axis defines the empirical frequency.

On the appearance of the histogram, as well as on the value of the coefficient of variation, put forward a hypothesis regarding the theoretical pattern of distribution.

Calculation of theoretical frequency. Calculate the density of the distribution function $\left(f\left(Y_{i}\right)\right)$ for each partial interval. For Weibull's theoretical distribution, we first need to find the parameters $a$ i $b$ [15].

For each partial interval, the theoretical frequency is calculated:

$$
P_{T i}(Y)=f(Y) \cdot \Delta Y,
$$

where DY - interval step.

Checking the proximity of empirical and theoretical distributions. The proximity between empirical and theoretical distribution is verified by criterion $\chi^{2}$ [15]. To this end, it is necessary to calculate a product for each partial interval $-N \times P_{T i}$.

Express the criterion by the formula:

$$
\chi^{2}=\sum_{i=1}^{k^{\prime}} \frac{\left(m_{i}-N \cdot P_{T i}\right)^{2}}{N \cdot P_{T i}}
$$

where $k^{\swarrow}$ - the number of intervals to match them.

Determine the number of degrees of freedom by the formula 


$$
r=k^{\prime}-(n+1)
$$

where $n$ - number of parameters of the theoretical distribution function.

By setting the level of significance $\alpha(\alpha=0,05 \ldots 0,1)$, we will find for a certain $r$, value $\left(\chi^{*}\right)^{2}$ and compare it with the calculated one. If $\chi^{2}<\left(\chi^{*}\right)^{2}$, then the theoretical distribution reflects the empirical data. Otherwise, the proximity between empirical and theoretical distribution is absent.

Production and computer experiments were conducted to achieve the stated purpose and to fulfill the tasks of the work. During the study of the potential of the region and the processes of electricity production from wind and solar energy, the methods of passive production observations, statistical data processing, simulation modeling, etc. were used.

The essence of production experiments is to create an information base on the main characteristics of the design objects and the design environment. Synthesis of theoretical studies and results of production experiments allows us to build the necessary model for estimating electricity production from wind and solar energy.

Determining the distribution of average power consumption of objects and seasonal irregularity is based on the analysis of retrospective data of electricity consumption of enterprises of Stryi district of Lviv region. In order to expand the sample needed to build the trend of seasonality of energy consumption, data from different farms should be normalized - leading to a unit of average monthly energy consumption:

$$
w_{i}(m)=12 \frac{W_{i}(m)}{\sum_{n=1}^{12} W_{i}(n)},
$$

where $W_{i}(m)$ - actual amount of energy, used by i-household during m-month, kW.h/month; $w_{i}(m)$ - the relative amount of energy.

The fluctuations in the sample statistics can be judged as random deviations from the average load charts.

The main parameter characterizing wind potential is the dynamics of wind speed change. Wind velocity and solar radiation distributions are constructed for each month of the year by processing an array of retrospective data from weather station observation logs.

\section{Research results and discussion}

Each of the periods of the year for a given region is characterized by the speed of wind flow, on which the choice of type of wind installation depends and the total amount of solar energy that influences the calculation and choice of solar photomodules [5, 9].

Statistical analysis of the obtained data on wind speed in the territory of Stryi district of Lviv region (northern strip of Ukrainian Carpathians) allowed to determine their numerical characteristics and to substantiate theoretical distribution laws, which are Weibull distributions (Fig. 1-4) 


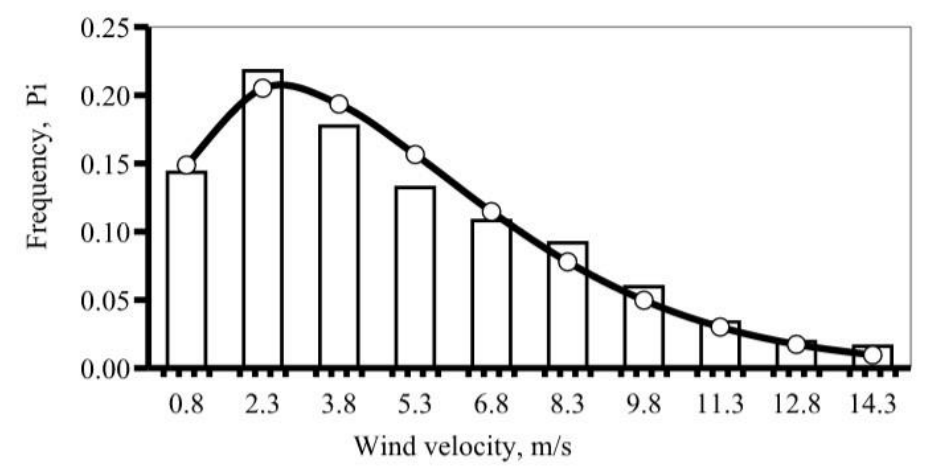

Fig. 1. Wind velocity distribution in the northern lane of the Ukrainian Carpathians (1st quarter). Wind velocity, $\mathrm{m} / \mathrm{s}$.

The estimation of the mathematical expectation of wind speed in the territory of a given region for the first quarter is $-4,88 \mathrm{~m} / \mathrm{s}$, the estimate of the standard deviation $-3,32 \mathrm{~m} / \mathrm{s}$., The coefficient of variation - 0,68. (Fig. 1). For the second quarter, the estimation of the mathematical expectation of wind speed on the territory of agricultural enterprises is 4.07 $\mathrm{m} / \mathrm{s}$, the estimate of the standard deviation is $3.2 \mathrm{~m} / \mathrm{s}$, the coefficient of variation is 0.78 . (Fig.2).

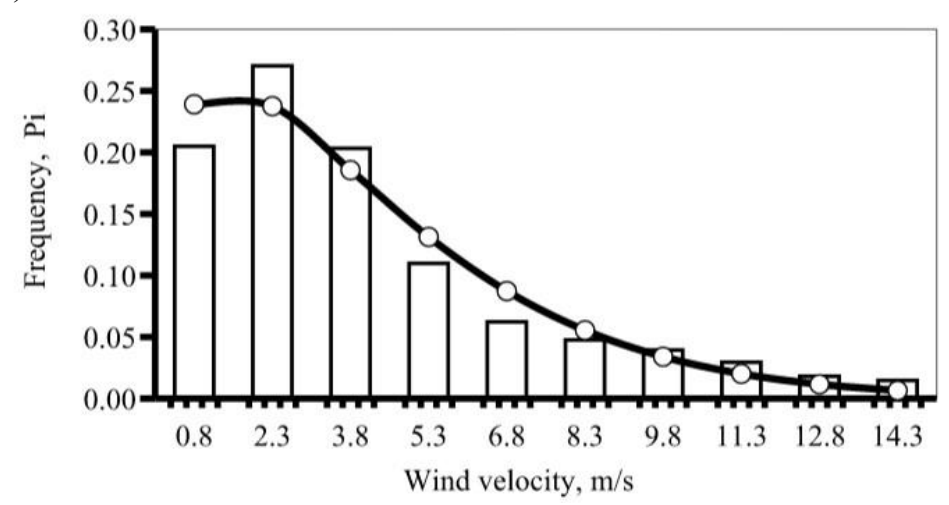

Fig. 2. Wind velocity distribution in the northern strip of the Ukrainian Carpathians (2rd quarter)

For the third quarter, the estimation of the mathematical expectation of wind speed on the territory of agricultural enterprises is $4.09 \mathrm{~m} / \mathrm{s}$, the estimate of the standard deviation is $3.13 \mathrm{~m} / \mathrm{s}$, the coefficient of variation is 0.76 . (Fig.3).

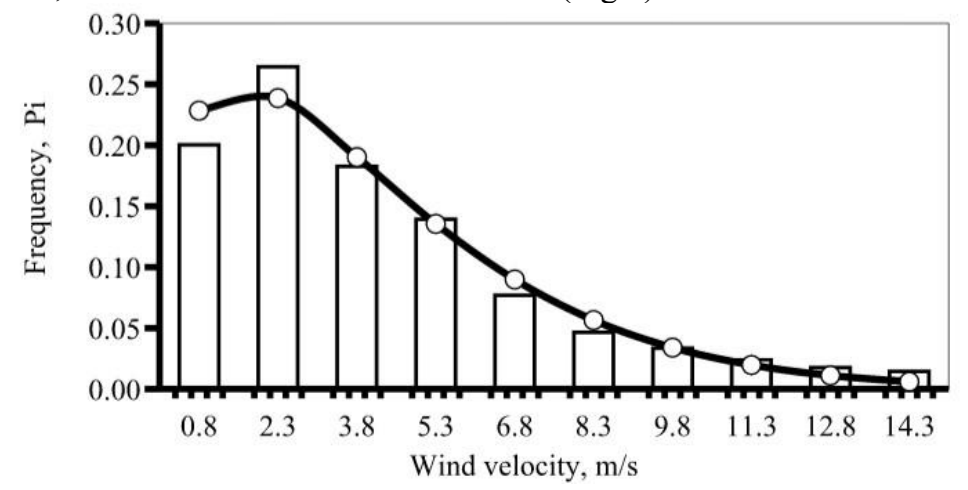

Fig. 3. Wind velocity distribution in the northern strip of the Ukrainian Carpathians (3rd quarter) 
For the fourth quarter, the estimation of the mathematical expectation of wind speed on the territory of agricultural enterprises is $4.36 \mathrm{~m} / \mathrm{s}$, the estimate of the standard deviation is $3.21 \mathrm{~m} / \mathrm{s}$, the coefficient of variation is 0.73 . (Fig. 4 ).

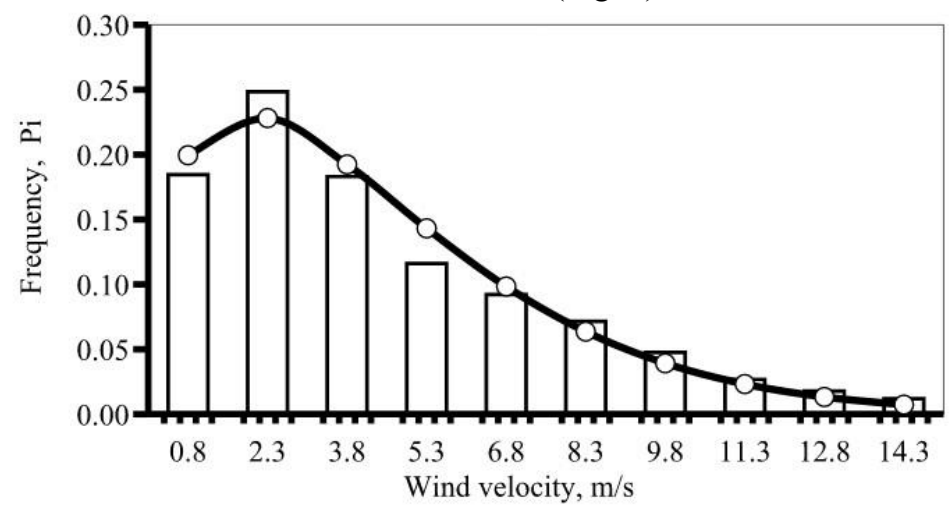

Fig. 4. Wind velocity distribution in the northern strip of the Ukrainian Carpathians (4th quarter)

Similarly, the statistical analysis of the received data on the total solar energy supply in the territory of the northern strip of the Ukrainian Carpathians was carried out, and the results are presented in Table. 2.

Table 2 - Mathematical expectation of total daily solar radiation, $\mathrm{cal} / \mathrm{cm}^{2}$

\begin{tabular}{|c|c|c|c|c|c|}
\hline $\begin{array}{l}\text { № } \\
\text { p/e }\end{array}$ & April & May & June & July & August \\
\hline 1 & - & - & 515,2 & 480,8 & 492.5 \\
\hline 2 & - & 406,8 & 511,2 & 499,7 & 489,8 \\
\hline 3 & - & 401,2 & 460,4 & 484,2 & 472,6 \\
\hline 4 & - & 389,4 & 507.2 & 488,8 & 499,1 \\
\hline 5 & - & 451,8 & 534,1 & 484,5 & 451 \\
\hline 6 & - & 473,3 & 533,2 & 472,4 & 407,6 \\
\hline 7 & - & 463,3 & 533,3 & 503,2 & 480,4 \\
\hline 8 & - & 433,7 & 547,9 & 488,8 & 430,5 \\
\hline 9 & - & 453,4 & 592,4 & 485,5 & 465,1 \\
\hline 10 & - & 471,6 & 510,4 & 463,1 & 450,3 \\
\hline 11 & - & 441,4 & 501,8 & 527,6 & 457,1 \\
\hline 12 & - & 431,2 & 502,9 & 527,3 & 405,9 \\
\hline 13 & - & 462,9 & 499.2 & 498,1 & - \\
\hline 14 & - & 441,7 & 535,5 & 542,7 & 408.5 \\
\hline 15 & - & 506,1 & 531,1 & 517,7 & 411,5 \\
\hline 16 & - & 495,7 & 537,3 & 49143 & 389 \\
\hline 17 & - & 474,9 & 500.3 & 498,7 & 405,6 \\
\hline 18 & 362,2 & 509,2 & 484,8 & 537,8 & 387,3 \\
\hline 19 & - & 525,2 & 505,8 & 438,7 & 375,1 \\
\hline 20 & - & 489,6 & 554,4 & 466,6 & 394,1 \\
\hline 21 & 383,1 & 506,8 & 522,2 & 478,8 & - \\
\hline 22 & 378,1 & 443,9 & 547,2 & 477,6 & 388,6 \\
\hline 23 & - & 406,6 & 572,2 & 468,6 & 391,1 \\
\hline 24 & - & 453 & 542.7 & 516,2 & - \\
\hline 25 & - & 415,5 & 579,3 & 485,8 & - \\
\hline 26 & - & 429,6 & 563,9 & 442,0 & - \\
\hline 27 & - & 445,9 & 552,4 & 458,7 & \\
\hline 28 & 464,8 & 474,2 & 522,4 & 431,3 & $3 \overline{68,5}$ \\
\hline 29 & 452,3 & 496,7 & 516,1 & 497,0 & 371,2 \\
\hline 30 & 423,9 & 502,6 & 489,4 & 511,4 & - \\
\hline 31 & - & 466,4 & - & 510,9 & 397,8 \\
\hline \multicolumn{2}{|c|}{ Total : 2833,1} & 13763,6 & 16336,2 & 15175.8 & 10586,8 \\
\hline
\end{tabular}


Total amount for a year: $55862.4 \mathrm{cal} / \mathrm{cm}^{2}\left(2327,6 \mathrm{MJ} / \mathrm{m}^{2}\right)$.

Subsequently, the simulation of electricity production was performed on the basis of the developed simulation model. In modeling the production of energy resources from solar and wind energy, the wind and solar potentials of the northern strip of the Ukrainian Carpathians were taken into account, which made it possible to construct appropriate daily schedules (Fig. 5 and 6).
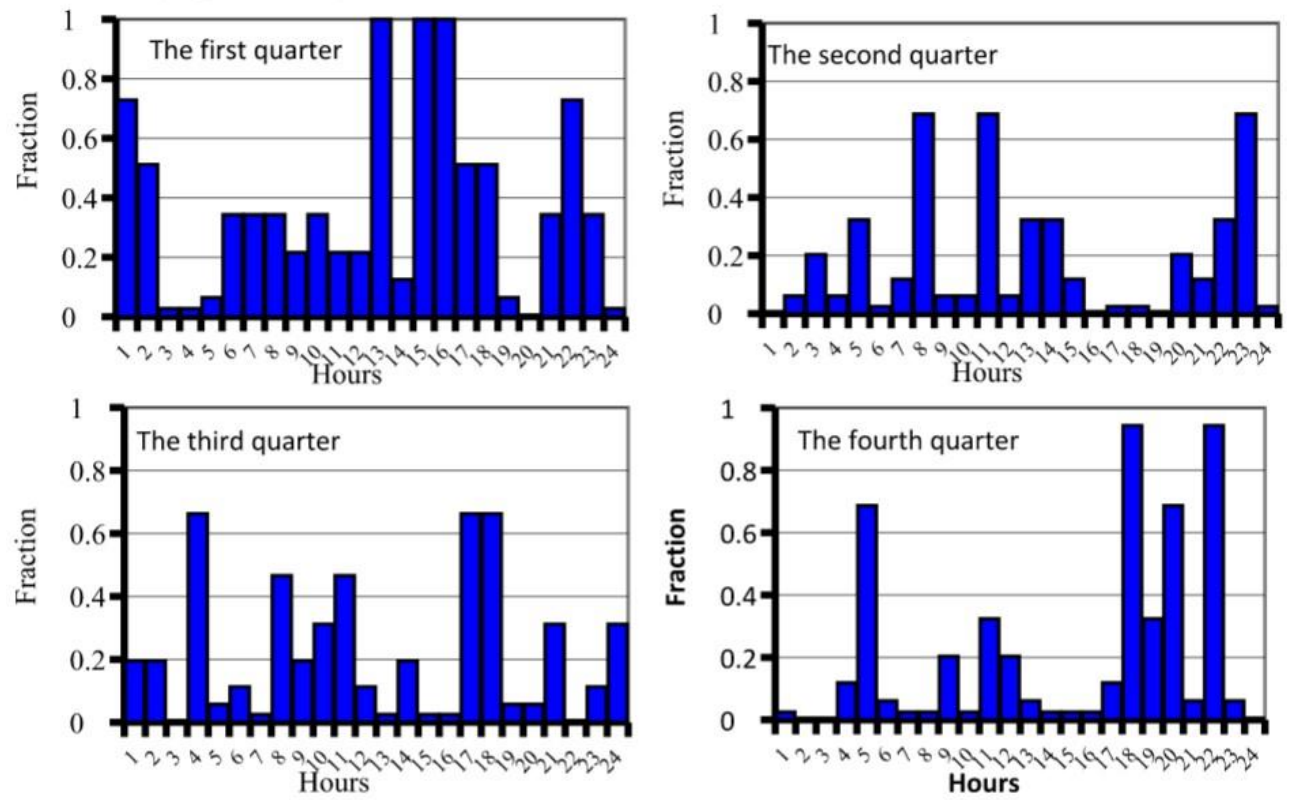

Fig. 5. Daily graphs of the relative generation of electricity by a wind power plant
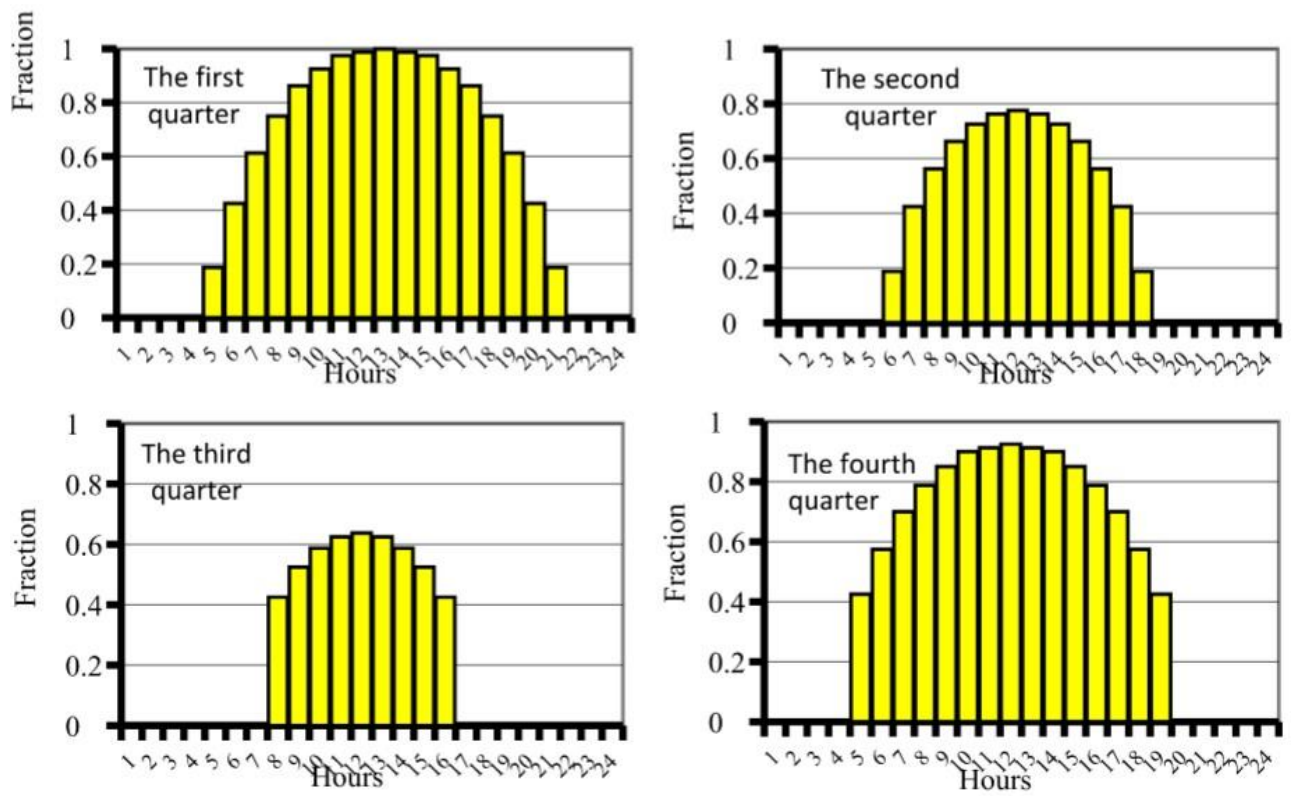

Fig. 6. Daily graphs of the relative generation of electricity from the solar electrical installation

The results show that for the efficient energy supply of objects from wind and sun 
energy in the northern strip of the Ukrainian Carpathians, combined systems should be formed. At the same time, their components will be both wind power plants and solar electric collectors, which will replace about $27 \%$ of electricity. The conducted research will be useful for the managers of projects of energy supply of objects from wind and solar energy in the northern strip of the Ukrainian Carpathians. They can also be used when designing such systems. The substantiated patterns of change in the natural potential of wind and solar energy, as well as the graphs of the relative generation of electricity from them, will significantly speed up managerial decisions and improve their quality.

\section{Conclusion}

Based on the conducted research, according to the Drohobych meteorological station, an energy assessment of wind and solar energy resources in the northern strip of the Ukrainian Carpathians was performed. It is substantiated that theoretical curves of distribution of wind speed in separate quarters of the year in the territory of the northern strip of the Ukrainian Carpathians are described by Weibull distributions with mathematical expectation, which fluctuates within $3.21 . .4 .09 \mathrm{~m} / \mathrm{s}$.

It is established that the highest amount of total daily solar radiation occurs in the summer months (Table 1). The performed researches made it possible to build daily schedules of relative generation of electricity by wind installations (Fig. 5) and solar electric installations (Fig. 6). Combined systems should be designed to provide efficient energy supply for wind and solar energy in the northern strip of the Ukrainian Carpathians. At the same time, their components will be both wind power plants and solar electric collectors, which will replace about $27 \%$ of electricity

\section{References}

1. J. Tastu, P. Pinson, E. Kotwa, H.Aa. Nielsen, H. Madsen. Spatio-temporal analysis and modeling of wind power forecast errors. Wind Energy 14, (2011)

2. J. Yan, T. Ouyang. Advanced wind power prediction based on data-driven error correction. Energy Conversion and Management. 180, (2019)

3. P. Pinson, H.Aa. Nielsen, H. Madsen, G. Kariniotakis. Skill forecasting from ensemble predictions of wind power. Applied Energy 86, (2009)

4. P. Pinson, H.Aa. Nielsen, J.K. Moeller, H. Madsen, G. Kariniotakis. Nonparametric probabilistic forecasts of wind power: required properties and evaluation. Wind Energy 10(6), (2007)

5. M. Yousif, Q. Ai, W. Ahmad Wattoo, Z. Jiang, Y. Gao. Least cost combinations of solar power, wind power, and energy storage system for powering large-scale grid. Journal of Power Sources. 412, (2019)

6. A. Gensler. Wind Power Ensemble Forecasting. Performance Measures and Ensemble Architectures for eterministic and Probabilistic Forecasts. 205, (2019)

7. A. Tealab. Time Series Forecasting using Artificial Neural Networks Methodologies: A Systematic Review. Future Comput. Inform. 3, (2018)

8. R. Jiao, X. Huang, X. Ma, L. Han, W. Tian. A model combining stacked auto encoder and back propagation algorithm for short-term wind power forecasting. IEEE Access. 6 , (2018)

9. Y. Wang, D. Xie, X. Wang, Y. Zhang. Prediction of Wind Turbine-Grid Interaction Based on a Principal Component Analysis-Long Short Term Memory Model. 11, (2018) 
10. Y. Zhang, C. Zhang, Y. Zhao, S. Gao. Wind speed prediction with RBF neural network based on PCA and ICA. J. Electr. Eng. 69, (2018)

11. T. Ouyang, X. Zha, L. Qin. A combined multivariate model for wind power prediction. Energy Conversion and Management. 144, (2017)

12. A.Tryhuba, R. Ratushny, O. Bashynsky, O. Shcherbachenko. Identification of firefighting system configuration of rural settlements. FESE. 247, (2018)

13. A. Tryhuba, O. Zachko, V. Grabovets, O. Berladyn, I. Pavlova, M. Rudynets. Examining the effect of production conditions at territorial logistic systems of milk harvesting on the parameters of a fleet of specialized road tanks. Eastern-European Journal of Enterprise Technologies. 95, (2018)

14. A. Tryhuba, O. Bashynskyi, S. Slobodian, D. Skorobogatov. Justification of models of changing project environment for harvesting grain, oilseed and legume crops. IJM\&P. Special Edition PDATU, (2019)

15. E. Hulida, I. Pasnak, O. Koval, A. Tryhuba, Determination of the Critical Time of Fire in the Building and Ensure Successful Evacuation of People. Periodica Polytechnica Civil Engineering. 63, (2019)

16. A. Tryhuba, N. Pavlikha, M. Rudynets, I. Tryhuba, V. Grabovets, M. Skalyga, I. Tsymbaliuk, N. Khomiuk, V. Fedorchuk-Moroz. Studying the influence of production conditions on the content of operations in logistic systems of milk collection. EasternEuropean Journal of Enterprise Technologies: Control processes. 99, (2019)

17. R. Ratushnyi, P. Khmel, A. Tryhuba, E. Martyn, O. Prydatko. Substantiating the effectiveness of projects for the construction of dual systems of fire suppression. EasternEuropean Journal of Enterprise Technologies: Control processes. 4, (2019)

18. J. Hu, J. Heng, J. Tang, M. Guo. esearch and application of a hybrid model based on Meta learning strategy for wind power deterministic and probabilistic forecasting. Energy Conversion and Management. 173, (2018)

19. S. Yermakov, T. Hutsol, O. Ovcharuk, I. Kolosiuk Mathematic simulation of cutting unloading from the bunker. Independent journal of management $\&$ amp; production (IJM\&P). Pp. 758-777 (2019)

20. S. Yermakov, K. Mudryk, T. Hutsol, K. Dziedzic, L. Mykhailova The analysis of stochastic processes in unloadingthe energywillow cuttings from the hopper.

Environment. Technology. Resources. Rezekne, Latvia. Proceedings of the 12th International Scientific and Practical Conference. Volume III. p. 249-252 (2019)

21. I. Usta, I. Arik, I. Yenilmez, Y. Mert Kantar. A new estimation approach based on moments for estimating Weibull parameters in wind power applications. Energy Conversion and Management. 164 (2018) 